\title{
Effect of Supraperiosteal Injection of Dexamethasone on Interappointment Pain in Teeth with Symptomatic Irreversible Pulpitis: A Comparative Study
}

Ajmal Yousaf ${ }^{1}$, Fatima Ali ${ }^{1}$, Syed Muzammil Hussain ${ }^{1}$, Faisal Bhangar ${ }^{1}$, Nasrin Yousaf ${ }^{2}$, Khurshid Ali Bangash ${ }^{3}$

\section{ABSTRACT}

Objective: To compare the effect of supraperiosteal injection of dexamethasone with $2 \%$ lidocaine on the frequency of interappointment endodontic pain at different time intervals.

Study Design: Prospective comparative study.

Place and Duration of Study: The study was carried out at operative department of Armed Forces Institute of Dentistry, Rawalpindi from $1^{\text {st }}$ October 2019 to $31^{\text {st }}$ March 2020.

Materials and Methods: A total of 100 patients presenting to the Department of Operative Dentistry, Armed Forces Institute of Dentistry, Rawalpindi and giving consent for participation, aged 20-50 years from both genders, presenting with acutely inflamed pulp in their maxillary first molars were selected for this study using convenient sampling technique. The patients were randomly divided into two equal groups of 50 patients with the help of scientific random number table. Endodontic therapy was initiated, pulpectomy canals were prepared with ProTaper Next system, intra-canal dressings of calcium hydroxide were placed and the cavity was restored with Cavit till the next appointment. Group A patients were then injected with dexamethasone at the mucobuccal fold and group B patients were injected with lidocaine used as placebo. Pain was recorded at 48 and 72 hours using the visual analogue scale. Data was analyzed using SPSS 21.

Results: The study included equal number of male and females. The mean age of group A was $35 \pm 4.5$ years while of group B was $33 \pm 6.7$ years. The results showed that dexamethasone does not reduce pain at 48 and 72 hours compared to the placebo.

Conclusion: It is concluded that dexamethasone does not reduce interappointment endodontic pain when compared to a placebo.

Key Words: Dexamethasone, Inter Appointment Pain, Lidocaine.

How to cite this: Yousaf A, Ali F, Hussain SM, Bhangar F, Yousaf N, Bangash KA. Effect of Supraperiosteal Injection of Dexamethasone on Interappointment Pain in Teeth with Symptomatic Irreversible Pulpitis: A Comparative Study. Life and Science. 2020; 1(4): 145-148. doi: http://doi.org/10.37185/LnS.1.1.111

This is an Open Access article distributed under the terms of the Creative Commons Attribution License (http://creativecommons.org/licenses/by/4.0), which permits unrestricted use, distribution, and reproduction in any medium, provided the original work is properly cited.

\section{Introduction}

One of the primary goals of endodontic treatment is management of pulpitis pain. ${ }^{1}$ Quick pain relief has

${ }^{1}$ Department of Operative Dentistry

Armed Forces Institute of Dentistry (AFID), Rawalpindi

${ }^{2}$ Department of Radiology

Quaid-e-Azam Hospital, Islamabad

${ }^{3}$ Department of Neurosurgery

Combined Military Hospital, Rawalpindi

Correspondence:

Lt Col Dr. Ajmal Yousaf

Department of Operative Dentistry

Armed Forces Institute of Dentistry (AFID), Rawalpindi

E-mail: bangashajmal@gmail.com

Funding Source: NIL; Conflict of Interest: NIL

Received: Apr 17, 2020; Revised: May 15, 2020

Accepted: Sep 15, 2020

145 not only a positive impact on the reducing patient anxiety but also ensures future compliance to the treatment. ${ }^{2}$ Endodontic pain can occur before, during or after endodontic treatment. Patients experiencing moderate to severe pain before treatment were found to be five times more likely to experience post-treatment pain. ${ }^{2}$ Failure to maintain canal patency and debriding the canal inadvertently irritates the peri-radicular tissues introducing bacterial products and necrotic pulp remnants. Postoperative pain after endodontic treatment can be due to infection or inflammation or both in the periradicular tissues. Certain factors may predispose to the development of post-operative endodontic pain like the number of appointments, time between 
successive appointments, use of intra-canal medicament and use of anti-inflammatory drugs. ${ }^{3}$ Managing endodontic pain includes all aspects of the treatment including anxiety reduction, controlling pre-operative pain, intra-operative pain and postoperative pain. ${ }^{2}$ Intra-operative pain control depends mainly on effective local anesthetic administration and primary and supplemental anesthetic techniques. ${ }^{4}$ The incidence of postoperative pain of low intensity is $2.53 \%$ to $58 \%$ and is a common event even following all the standard protocols of endodontic therapy. Management of interappointment pain before a patient is recalled for the next procedure is important. Controlling this pain involves a variety of techniques and pharmacological agents. ${ }^{5}$ Some commonly used methods for managing interappointment endodontic pain include using pre-treatment steroids and nonsteroidal anti-inflammatory drugs (NSAID), intracanal medicaments in between appointments, irrigant activation, crown down technique of root canal preparation which reduces apical extrusion and providing occlusal relief. ${ }^{6,7}$

Considering the influence of prostaglandins on interappointment pain, a possible strategy to reduce pain would be to use anti-inflammatory agents locally at the site of infection of the inflamed tooth to decrease the local production of prostaglandins. Dexamethasone is a potent anti-inflammatory glucocorticoid which can be used for this purpose. Mehrvarzfar et al $^{9}$ has shown that the supraperiosteal injection of dexamethasone can reduce interappointment endodontic pain in teeth presenting with irreversible pulpitis.

The purpose of this study was to compare the effect of supraperiosteal injection of dexamethasone compared with $2 \%$ lidocaine with epinephrine $1: 100,000$ used as a placebo on the frequency of interappointment endodontic pain at different time intervals.

\section{Materials and Methods}

After taking approval from the ethical committee (No 905/Trg-ABP1K2), this study was done at the Operative Department, Armed Forces Institute of Dentistry Rawalpindi from $1^{\text {st }}$ October 2019 to $31^{\text {st }}$ March 2020. After taking informed consent, 100 patients from 20-50 years of age of both genders with good general health were selected for this study using convenient sampling technique and were randomly divided into two equal groups with the help of scientific random number table.

The sample size was calculated by using the WHO calculator. With a level of significance $5 \%$, with power of test kept at $95 \%$, a total sample size of 74 patients was calculated which was increased to 100 patients to cater for the loss of follow up. Following population proportions were used. ${ }^{9}$ Population proportion $A=65 \%$;Population proportion $B=25 \%$

The maxillary first molars with acutely inflamed pulp without swelling or draining sinus were selected for this study. Patients on preoperative analgesics and antibiotics, teeth with calcified canals and previously treated teeth, pregnant and lactating mothers, mandibular molars (because of compact bone of mandible) were all excluded from this study. The patients were screened for inclusion by taking history, relevant clinical examination and peri-apical radiographs. After selection, the procedure was explained to the patient and they were randomly divided into two groups. Root canal treatment was then initiated under local anesthesia and rubber dam isolation. Working length was taken with apex locator and confirmed with radiograph. The root canals were instrumented with ProTaper Next system under copious irrigation with $5.25 \%$ sodium hypochlorite $(\mathrm{NaOCl})$. Patency was confirmed with a \#10 K file between each instrument change. The root canals were flushed with $5 \mathrm{~mL}$ of $17 \%$ EDTA solution. To control the microbiological impact on postoperative pain calcium hydroxide was used as an intra-canal medicament and likewise $2.5 \%$ sodium hypochlorite as an irrigant in both groups. Following instrumentation and calcium hydroxide placement in the canal using lentulo spirals the cavity was temporarily sealed with Cavit.

Group A were injected with $4 \mathrm{mg} / \mathrm{ml}$ Dexamethasone (Dexamek, Karachi Pharma containing Dexamethasone Phosphate $4 \mathrm{mg} / 1 \mathrm{ml}$ ) at the mucobuccal fold using the $\mathrm{U}-40$ insulin syringe of 30 gauge and $8 \mathrm{~mm}$ short needle.

Group B were injected with $2 \%$ lidocaine w/epinephrine 1:100,000 (Lignocaine $\mathrm{HCL}$ Septodont USA) at the mucobuccal fold using the lidocaine cartridge in the dental infiltration needle of 27 gauge and $25 \mathrm{~mm}$ long needle.

At the end of appointment each patient was given a 
Visual Analogue Scale (VAS). The patient was advised to mark the line corresponding with the intensity of his pain at 48 and 72 hours after the first visit. The patient was recalled after one week for obturation and final full coverage restoration.

The data was analyzed using SPSS 21 . Frequencies and percentages are presented for pain (no pain $=0$, mild pain $=<3$, moderate pain $=>4$, severe pain $=>7$ ). Chi-Square test was used to compare interappointment endodontic pain for group $A$ and group $B$ at 48 hours and 72 hours after completion of the treatment. A $p$ value of less than 0.05 was considered significant.

\section{Results}

The study had equal number of male and females. Mean age of group A was $35 \pm 4.5$ years while of group B was $33 \pm 6.7$ years.

\begin{tabular}{|c|c|c|c|}
\hline Pain & $\begin{array}{l}\text { Group A }(n=50) \\
\text { Dexamethasone }\end{array}$ & $\begin{array}{l}\text { Group B } \\
(n=50) \\
\text { Lidocaine as } \\
\text { placebo }\end{array}$ & $p$-value \\
\hline \multicolumn{4}{|c|}{ After 48 hours } \\
\hline No Pain & $5(10 \%)$ & $7(14 \%)$ & \multirow{4}{*}{0.89} \\
\hline Mild Pain & $27(54 \%)$ & $28(56 \%)$ & \\
\hline $\begin{array}{l}\text { Moderate } \\
\text { Pain }\end{array}$ & $12(24 \%)$ & $10(20 \%)$ & \\
\hline $\begin{array}{l}\text { Severe } \\
\text { Pain }\end{array}$ & $6(12 \%)$ & $5(10 \%)$ & \\
\hline \multicolumn{4}{|c|}{ After 72 hours } \\
\hline No Pain & 17 (34\%) & $15(30 \%)$ & \multirow{4}{*}{0.60} \\
\hline Mild Pain & $27(54 \%)$ & $24(48 \%)$ & \\
\hline $\begin{array}{l}\text { Moderate } \\
\text { Pain }\end{array}$ & $4(8 \%)$ & $8(16 \%)$ & \\
\hline $\begin{array}{l}\text { Severe } \\
\text { Pain }\end{array}$ & $2(4 \%)$ & $3(6 \%)$ & \\
\hline
\end{tabular}

\section{Discussion}

The occurrence of interappointment endodontic pain is not an unusual event and is quite frequent even after following all the standard treatment protocols. According to studies ${ }^{10}$, there is $4-10 \%$ occurrence of moderate inter appointment pain after endodontic treatment while studies have also reported an even higher incidence till 58\%. ${ }^{11}$ Inter appointment pain can be caused by either mechanical, microbial and or chemical insults to either the pulp or the peri-radicular structures which are often exacerbated after initiating endodontic treatment. ${ }^{1,2}$ The pain occurs due to the release of local prostaglandins, leukotriene, bradykinin and serotonin. These substances in turn activate the nociceptors eliciting the sensation of pain in the tooth.

Various classes of drugs have been employed for managing interappointment endodontic pain including NASIDS, acetaminophen, corticosteroids and opioids. ${ }^{12}$ Out of these, NSAIDS are of importance because they inhibit the formation of prostaglandins by inhibiting the COX 1 and COX 2 enzymes. However, their multiple side effects due to non-selectivity limit their use for managing interappointment endodontic pain. ${ }^{13}$

Corticosteroids have an immediate effect in reducing pain after endodontic therapy by suppressing inflammatory mediators. ${ }^{14}$ Corticosteroids have long been used in dentistry in various forms. ${ }^{15}$ Patients mostly experience pain during the initial 24 to 72 hours period. ${ }^{16}$ Results of a systemic review concluded that the major effects of steroids on pain reduction occur during 24-72 hours period and this also coincides with our study. ${ }^{17}$ Our study results showed that infiltration of dexamethasone does not reduce pain when compared to a placebo.

In a study similar to ours, Mehrvarzfar et $\mathrm{al}^{9}$ concluded that local infiltration of dexamethasone into the PDL does significantly reduce inter appointment endodontic pain in teeth with irreversible pulpitis. A study conducted by Mehrvarzfar et $\mathrm{al}^{18}$ on the supraperiosteal infiltration of dexamethasone concluded that dexamethasone was effective in reducing pain at 24 hours but after 48 hours both dexamethasone and placebo had a similar effect on pain reduction.

Shantiaee et al $^{19}$ compared the efficacy of peri-apical infiltration of dexamethasone, morphine and placebo on the interappointment pain and concluded that dexamethasone was more effective in reducing pain than both morphine and placebo after 24 hours. Our results have shown that dexamethasone does reduce interappointment pain but these results were not statistically significant. Kaufman et $\mathrm{al}^{20}$ evaluated the effect of intraligamentary corticosteroid on interappointment endodontic pain using methylprednisolone in comparison to a placebo group. The results showed 
that local steroid infiltration does reduce interappointment pain compared to a placebo. Another study by Gallatin et al ${ }^{21}$ on interappointment in patients with irreversible pulpitis showed similar results with decreased interappointment endodontic pain. Bramy et $\mathrm{al}^{22}$ evaluated interappointment endodontic pain using local steroid infiltration in necrotic teeth and the results showed reduced incidence of pain.

Limitation of this study is that only one steroid was compared with the placebo and sample size was small.

\section{Conclusion}

Within the limitations of this study, it is concluded that more studies need to be carried out to evaluate the type of steroid and the dosage needed to manage interappointment pain.

\section{REFERENCES}

1. Lu Y, Liu Z, Huang J, Liu C. Therapeutic effect of one-time root canal treatment for irreversible pulpitis. Journal of International Medical Research. 2019; 16: 0300060519879287.

2. Shresha R, Shrestha D, Kayastha R. Post-operative pain and associated factors in patients undergoing single visit root canal treatment on teeth with vital pulp. Kathmandu Univ Med J. 2018; 62:120-3.

3. Abouelenien SS, Ibrahim SM, Shaker OG, Ahmed GM. Evaluation of postoperative pain in infected root canals after using double antibiotic paste versus calcium hydroxide as intra-canal medication: A randomized controlled trial. F1000Res. 2018; 7: 1768.

4. Saxena P, Chandra A, Gupta S, Newaskar V. Advances in dental local anesthesia techniques and devices: An update. Natl J Maxillofac Surg. 2013; 4: 19-24.

5. Jayakodi H, Kailasam S, Kumaravadivel K, Thangavelu B, Mathew S. Clinical and pharmacological management of endodontic flare-up. J Pharm Bioall Sci. 2012; 2: S294-8.

6. Hamid EA, Aziz SA, Sadek HS, Ibrahim AM. Effectiveness of triple antibiotic paste as an intra-canal medication for the root canal treatment of non-vital teeth with apical periodontitis: A systematic review F1000Res. 2018; 7: 1627.

7. AlRahabi M. Predictors, prevention, and management of postoperative pain associated with nonsurgical root canal treatment: A systematic review. J Taibah Univ Med Sci. 2017; 12: 376-84.

8. Ranmanesh F, Parirokh M, Haghdoost AA, Abbott PV. Effect of corticosteroids on pain relief following root canal treatment: A systematic review. Iran Endod J. 2017; 12: 123-30.
9. Mehrvarzfar P, Shababi B, Sayyad R, Fallahdoost A, Kheradpir K. Effect of supraperiosteal injection of dexamethasone on postoperative pain. Aust Endod J. 2008; 34: 25-9.

10. Wong AW, Zhang $\mathrm{C}$, Chu $\mathrm{CH}$. A systematic review of nonsurgical single-visit versus multiple-visit endodontic treatment. Clin Cosmet Investig Dent. 2014 ; 6: 45-56.

11. DiRenzo A, Gresla T, Johnson BR, Rogers M, Tucker D, BeGole EA. Postoperative pain after 1- and 2-visit root canal therapy. Oral Surg Oral Med Oral Pathol Oral Radiol Endod. 2002; 93: 605-10.

12. Smith E, Marshall J, Selph S, Barker D, Sedgley C. Nonsteroidal Anti-inflammatory Drugs for Managing Postoperative Endodontic Pain in Patients Who Present with Preoperative Pain: A Systematic Review and Metaanalysis. J Endod. 2017; 43: 7-15.

13. Harirforoosh S, Asghar W, Jamali F. Adverse Effects of Nonsteroidal Antiinflammatory Drugs: An Update of Gastrointestinal, Cardiovascular and Renal Complications. J Pharm Pharm Sci. 2014; 16: 821-47.

14. Pogatzki-Zahn E, Segelcke D, Schug S. Postoperative pain-from mechanisms to treatment. PAIN Rep. 2017; 2: e588.

15. Nath R, Daneshmand A, Sizemore D, Guo J, Enciso R. Efficacy of corticosteroids for postoperative endodontic pain: A systematic review and meta-analysis. J Dent Anesth Pain Med. 2018; 18: 205-21

16. Menakaya IN, Adegbulugbe IC, Oderinu OH, Shaba OP. The Efficacy of Calcium Hydroxide Powder mixed with $0.2 \%$ Chlorhexidine Digluconate or mixed with Normal Saline as Intracanal Medicament in the Treatment of Apical Periodontitis. The journal of contemporary dental practice. 2015; 16: 657-64.

17. Jafarzadeh H, Mohammadi Z, Shalavi S, Sahebalam R, Kinoshita J. Additive and reducing effects between calcium hydroxide and current irrigation solutions. J Contemp Dent Pract. 2017; 18: 246-9.

18. Mehrvarzfar P, Esnashar E, Salmanzadeh R, Fazlyab M, Fazlyab M. Effect of dexamethasone intraligamentary injection on post-endodontic pain in patients with symptomatic irreversible pulpitis: a randomized controlled clinical trial. Iran Endod J. 2016; 11: 261-6.

19. Shantiaee $Y$, Mahjour F, Dianat O. Efficacy comparison of periapical infiltration injection of dexamethasone, morphine and placebo for postoperative endodontic pain. I Dent J. 2012; 62: 74-8.

20. Gallatin E, Reader A, Nist R, Beck M. Pain reduction in untreated irreversible pulpitis using an intraosseus injection of depo-medrol. J Endod. 2002; 26: 633-8.

21. Schroder A. Endodontics-Science and Practice. Quintessence Publishing Co, Chicago. 1981: 44-58.

22. Bramy $E$, Reader A, Beck M, Weaver J. The intra-osseous injection of Depo-medrol on postoperative endodontic pain in symptomatic, necrotic teeth. J Endod. 1999; 25: 289. 